\title{
Laser Notching Ceramics for Reliable Fracture Toughness Testing
}

\author{
Holly D. Carlton ${ }^{*}$, John W. Elmer ${ }^{1}$, Dennis C. Freeman ${ }^{1}$, Ronald D. Schaeffer ${ }^{2}$, Oleg
}

Derkach $^{2}$, and Gilbert F. Gallegos ${ }^{1}$

\author{
${ }^{1}$ Lawrence Livermore National Laboratory, Livermore, CA 94550 USA \\ 2Photomachining, Inc. Pelham, NH 03-76 USA
}

\begin{abstract}
A new method for notching ceramics was developed using a picosecond laser for fracture toughness testing of alumina samples. The test geometry incorporated a singleedge-V-notch that was notched using picosecond laser micromachining. This method has been used in the past for cutting ceramics, and is known to remove material with little to no thermal effect on the surrounding material matrix. This study showed that laser-assisted-machining for fracture toughness testing of ceramics was reliable, quick, and cost effective. In order to assess the laser notched single-edge-V-notch beam method, fracture toughness results were compared to results from other more traditional methods, specifically surface-crack in flexure and the chevron notch bend tests. The results showed that picosecond laser notching produced precise notches in post-failure measurements, and that the measured fracture toughness results showed improved consistency compared to traditional fracture toughness notching methods.
\end{abstract}

Keywords: Ceramics; Fracture toughness; Laser notching; Single-edge-V notch beam; Alumina

* Corresponding author: Holly D. Carlton (Barth), email: barth4@llnl.gov, phone \#: +1-925-

422-2765, fax \#: +1-925-423-1572, Address: 7000 East Ave, Livermore, CA, USA 94550

(C) 2015. This manuscript version is made available under the Elsevier user license

http://www.elsevier.com/open-access/userlicense/1.0/ 


\section{Introduction}

There is a wide range of methods to evaluate a ceramic's fracture toughness and method selection can be material and resource dependent. Many ceramics display brittle characteristics and are highly sensitive to flaws. For ceramics, flaws can be found at many length-scales in the form of pores, inclusions, grain boundaries, and machining defects $[1,2]$. However, the pre-existing defect distribution in a ceramic specimen is not always known and can be time consuming to characterize. During fracture toughness testing a known worst-case flaw is introduced into the material and then the energy required to fracture the material is determined [3]. When selecting a fracture toughness method it is imperative that the specimen geometry involve either notches or pre-cracks that are reliable, reproducible and avoid introducing unwanted damage, in order to create accurate test results.

Two common specimen geometries used for calculating fracture toughness in ceramics are shown in Figure 1. The chevron notch $(\mathrm{CN})$ method has a sharp V introduced into the width of the bend specimen, and the surface-crack in flexure (SCF) method, where a pre-crack is introduced via a micro-hardness indenter [4-6]. Recently though singleedge- $\mathrm{V}$ notched beam (SEVNB) has shown promise as a reliable method for calculating fracture toughness in ceramics [7-12]. The specimen geometry for a SEVNB test calls for a sharp $\mathrm{V}$ in a different orientation than the $\mathrm{CN} \mathrm{V}$ and is based on straight-through cracks and does not require the addition of pop-in cracks [13]. A schematic showing the different geometries is presented in Figure 1. In preparing the SEVNB specimen the 
notch is commonly introduced via scribing, which is often done using a razor blade and diamond suspension. However the sharp radius necessary for the fracture toughness test is limited by the achievable radius, which is constrained by the thickness of the blade used for notching. This can be problematic for fracture toughness testing in brittle materials, because when the root radius of the notch is larger than relevant microstructural features the fracture toughness results will be adversely affected by the size effect [12], where the fracture toughness values are shown to vary with the square root of the radius until a critical root radius is achieved $[14,15]$. Therefore, for this study we investigated an alternative for notching ceramics for fracture toughness testing utilizing laser-assisted-machining with pulses in the picosecond (ps) range.
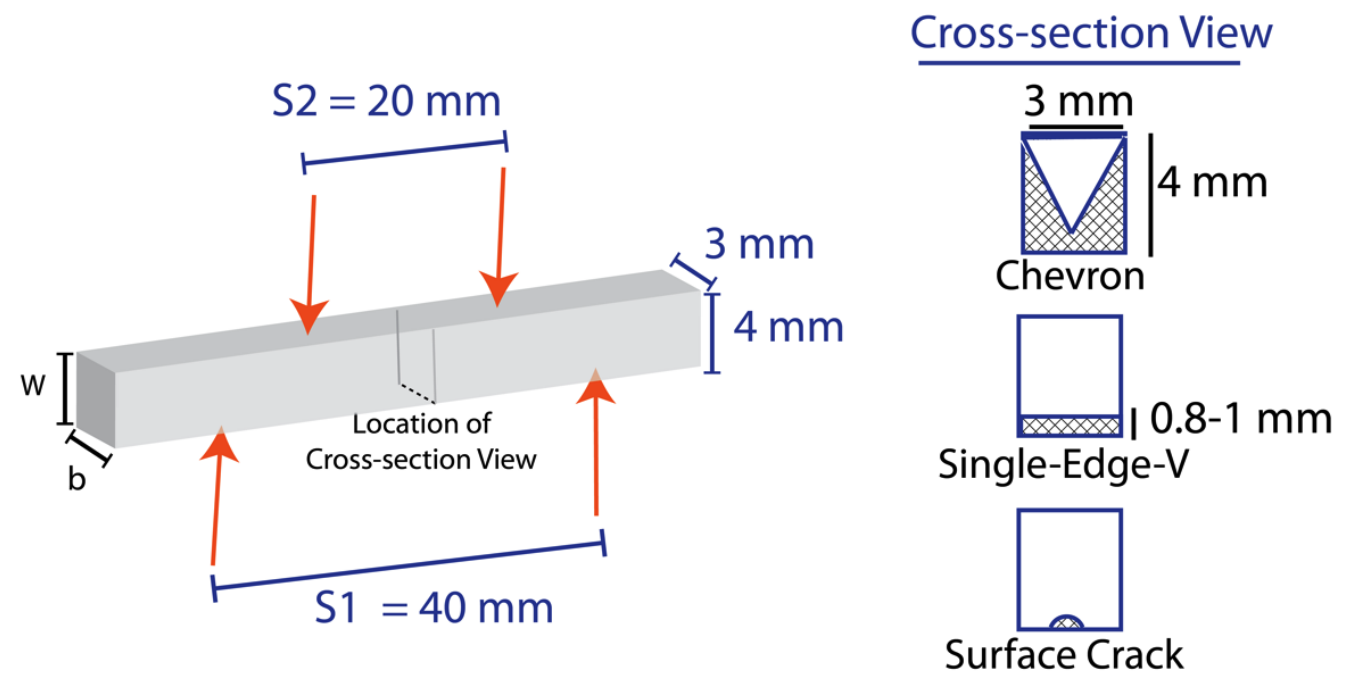

Figure 1. Specimen geometry. A notched rectangular alumina specimen $(3 \times 4 \times 45 \mathrm{~mm})$ is taken to failure using a four-point bend configuration. Also shown here on the right is a cross section through the sample (see location) with drawings of the three sample geometries used in this study. The three methods investigated here are CN, SEVNB, and SCF. All the notching was done on the $3 \mathrm{~mm}$ face for consistency. 
The benefits for the ps-laser are made possible by the fact that material removal occurs by ablation, whereby energy transferred to the surrounding lattice is insignificant. The result is that material is removed with little or no thermal effect on the surrounding material [16], and produces smooth reproducible notches. Another study [17] that was going on concurrently to this one, showed the benefits of using an ultra-short pulsed femtosecond laser to introduce shallow notches (20-40 $\mu \mathrm{m}$ depth) into zirconia with submicron grain size for fracture toughness testing. However, for the study presented here, the relative crack depth used for the SEVNB tests on ceramics is much larger, $\sim 25 \%$ versus $1 \%$, which eliminates the need to measure any beginner micro-cracks around the notch tip.

For this study we used a ps laser to introduce a notch that tapers to a V-shape for SEVNB fracture toughness testing. This method is used to evaluate the fracture toughness of three different purities of aluminum oxide $(96 \%, 97.5 \%$, and $99.5 \%)$, and the results are compared with two more traditional methods. The three purities of aluminum oxide were selected to observe the effects of notching on ceramics with varying toughness values. Specifically, the three types of purities have different grain sizes, which is known to influence the fracture behavior in aluminum oxide [18]. Also, these types of aluminum oxides are known to display some toughness in the form of stable crack growth once a crack initiates. 


\section{Experimental Methods}

\subsection{Laser Notching}

The laser notching for the SEVNB specimen was performed using a Lumera Super Rapid Q-switched DPSS laser with pulses in the picosecond range [19]. The laser notching parameters, i.e., laser wavelength, focal length, power, energy/pulse, pulse rate, and pulse length, were selected by making and assessing practice cuts to a sacrificial piece of alumina $\left(99.5 \% \mathrm{Al}_{2} \mathrm{O}_{3}\right)$. These tests were done with pre-selected parameters that would optimize cutting speed and notch quality, as summarized in Table 1. Here, two ps laser wavelengths were tested, infrared $(1064 \mathrm{~nm})$ and ultraviolet $(355 \mathrm{~nm})$. The laser power was $12 \mathrm{~W}$ in the infrared and $4 \mathrm{~W}$ in the $\mathrm{UV}$, and the laser beam diameter was kept constant at 25-30 $\mu \mathrm{m}$ using a lens focal length of $80 \mathrm{~mm}$ when in the infrared and 100 $\mathrm{mm}$ when in the ultraviolet. After inspecting the trial laser-assisted-machining cuts, we selected the UV set of parameters, which are shown in Row 2 of Table 1 for SEVNB testing reported in this study.

Table 1. Summary of the laser types and pulsing parameters used to optimize the laser assisted notching. The beam was focused to a diameter of $25-30 \mu \mathrm{m}$, which was scanned over the alumina surface at $500 \mathrm{~mm} / \mathrm{s}$.

\begin{tabular}{|c|c|c|c|c|c|}
\hline $\begin{array}{c}\text { Laser Type } \\
\text { (Wavelength) } \\
(\mathrm{nm})\end{array}$ & $\begin{array}{c}\text { Lens Focal } \\
\text { Length } \\
(\mathrm{mm})\end{array}$ & $\begin{array}{c}\begin{array}{c}\text { Nominal } \\
\text { Laser Power }\end{array} \\
\text { (W) }\end{array}$ & $\begin{array}{c}\text { Energy/Pulse } \\
\text { (ml) }\end{array}$ & $\begin{array}{c}\text { Pulse Rate } \\
\text { (kHz) }\end{array}$ & $\begin{array}{c}\text { Pulse } \\
\text { Length } \\
\text { (ps) }\end{array}$ \\
\hline $\begin{array}{c}\text { ps DPSS } \\
\text { Infrared (1064) }\end{array}$ & 80 & 12 & 0.12 & 100 & 10 \\
\hline $\begin{array}{l}{ }^{*} \text { ps DPSS } \\
\text { UV(355) }\end{array}$ & 100 & 4 & 0.04 & 100 & 10 \\
\hline
\end{tabular}

*Selected parameters for laser notching the SEVNB specimen for this study. 
The laser, which was pulsed during notching, was capable of operating at pulsing rates as high as $1 \mathrm{MHz}$. However, for our study the micromachining was performed at a 100 $\mathrm{kHz}$ pulse rate based on prior experience with laser machining ceramics. At $100 \mathrm{kHz}$, the pulse rates of the laser allowed for fast travel speeds of $500 \mathrm{~mm} / \mathrm{s}$, which was used in this investigation to produce a pulse-to-pulse pitch of approximately $5 \mu \mathrm{m}$. This pitch produces approximately $80 \%$ overlap of subsequent pulses, and created a smooth bottomed cut. All of the laser micromachining was performed in air with no additional gas shielding.

Once the parameters were developed the ps-laser was used to remove material to produce a notch with a specific depth, a, through the sample thickness, $B$, for the SEVNB specimen, as illustrated in Figure 1. The notch depth $a$ was selected so that the ratio, $a / W$, known as the normalized crack size, fell in a valid range: $0.2-0.3$ [4] (where $W$ is the specimen's width and is defined in Figure 1). The cutting times are proportional to the notch depths, but are very fast compared to the other methods. For the parameters used here, it took 40 passes to complete a $\sim 1 \mathrm{~mm}$ deep notch in the $99.5 \%$ purity alumina. At the travel speed of $500 \mathrm{~mm} / \mathrm{s}$ and a sample thickness of $3 \mathrm{~mm}$, the entire notch was completed in less than $1.5 \mathrm{~min}$. This includes the cutting time required to remove extra material near the original alumina surface, which allows the notch to form properly. 


\subsection{Traditional Fracture Toughness Tests}

The SCF and CN test specimens were machined using a high precision surface grinder, to a geometry similar to what is specified in the ASTM standard for determining fracture toughness of ceramics [4]. The SCF fracture toughness test used a Knoop indenter to introduce a semi-elliptical surface crack $[5,6]$ into the ceramic, which acts as a starter crack when brought to failure in a four-point bend configuration. The Knoop indenter was selected for introducing the surface crack over other types of indenter tips since it produces a much shallower indentation and it has been shown to be less susceptible to cracking problems [20]. Although the ASTM standard calls for a indentation load of less than $100 \mathrm{~N}$, it was determined by the operator that a load of $220 \mathrm{~N}$ was needed in order to pop in a pre-crack that could be resolved in post examination, as well as to make sure the indent spanned several grains. Figure 2a shows an optical micrograph $(\mathrm{OM})$ of a Knoop indented alumina specimen with visible cracks extending approximately $0.5 \mathrm{~mm}$ across the width of the indentation, and localized cracking or crushing near the central portion of the indentation. In future tests this crushing zone should be polished and removed per the ASTM standard 1421. 


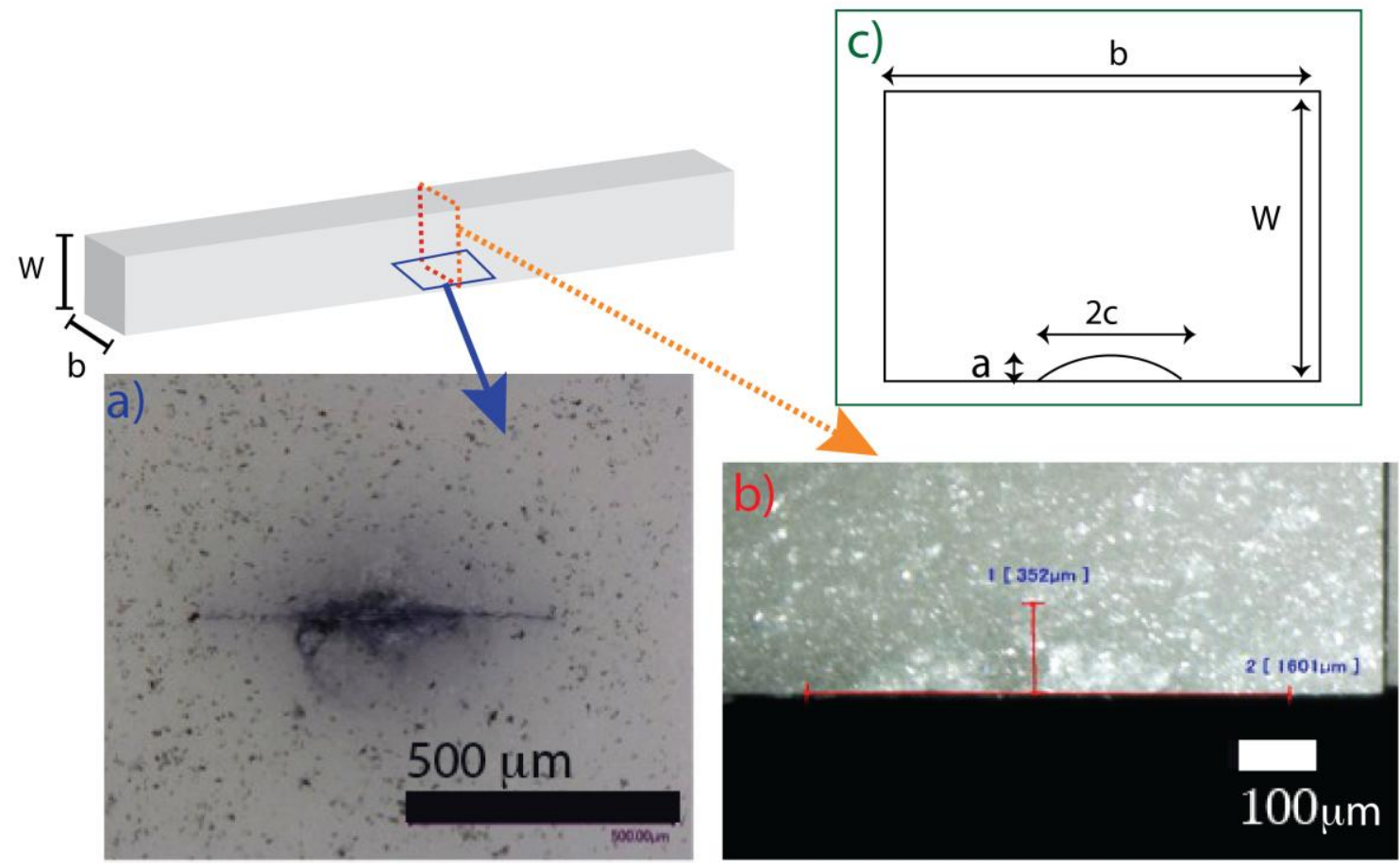

Figure 2. Knoop SC indentation pre-crack images. a) OM showing crack growth from a Knoop indentation on the surface of an aluminum oxide sample. b) OM of the cross section of a sample taken post fracture showing the measurement of the semi-elliptical pre-crack formed via the Knoop indent. c) schematic of the pre-crack configuration.

For the $\mathrm{CN}$ specimens a notch was introduced by machining the chevron using a diamond wafering blade attached to a surface grinder (Chevalier FSG-2A818). Custombuilt fixtures were required for machining the chevron geometry into the rectangular beam specimen. After machining the chevron into the ceramic specimen, it was loaded in a four-point bend configuration. The $\mathrm{CN}$ sample geometry allows for the preferred crack initiation site to occur at the tip of the chevron, which allows for a sharp crack to develop during loading. This notch geometry is designed to promote stable crack 
growth at the tip of the triangular notch until catastrophic failure. The $\mathrm{CN}$ method is generally preferred over the SCF method because it produces more consistent results if the notch is properly machined. However, the precision fixtures were expensive to fabricate and the low speed saw cutting was time consuming, adding considerable cost to the test plan.

\subsection{Materials, Test Specimen Geometries, and Mechanical Testing}

The materials studied here were $96 \%, 97.5 \%$, \& 99.5\% pure, polycrystalline aluminum oxide. Density, grain size and porosity for each type of alumina are presented in Table 2. The grain size for the $97.5 \%$ alumina is $3-4 \mathrm{x}$ larger than the other two types of alumina, which is a contributing factor in fracture toughness, in addition to purity. The 96\% CoorsTek alumina was procured as uncertified material, meaning that there may be more variability in the microstructure and fracture toughness than the other materials.

Table 2. Information on manufacturer, density, and grain size for the three purities of aluminum oxide tested for this study.

\begin{tabular}{llll}
\hline & 96\% Alumina & $\mathbf{9 7 . 5 \%}$ Alumina & 99.5\% Alumina \\
\hline Manufacturer & CoorsTek & Morgan Technical & Alfa Aesar (Al-23) \\
(Material) & & Ceramics (AL 300) & \\
Apparent Density & $\sim 3.72 \mathrm{~g} / \mathrm{cm}^{3}$ & $3.76 \mathrm{~g} / \mathrm{cm}^{3}$ & $3.7-3.95 \mathrm{~g} / \mathrm{cm}^{3}$ \\
& & & \\
Grain Size & $\sim 7 \mu \mathrm{m}$ & $\sim 30 \mu \mathrm{m}$ & $10 \mu \mathrm{m}$ \\
\end{tabular}


The bend specimens for the tests were machined from the as-received alumina plates into rectangular samples having a nominal width, $W$, thickness, $B$, and length, $L$, of 4,3 , and $45 \mathrm{~mm}$, respectively. For the SCF specimen surface cracks on the ceramic material were created with a Knoop indenter installed to a low capacity electro-mechanical test machine. All strength [21] and fracture toughness tests were performed in a four-point bend configuration with an outer span of $40 \mathrm{~mm}$ and inner span of $20 \mathrm{~mm}$ as indicated in Fig. 1 per ASTM Standard C1161 and 1421. Each test was conducted in ambient temperatures using a computer controlled (Instron 4444) electro-mechanical test machine with $1 \mathrm{kN}$ load cell. For each test the crosshead was controlled at a crosshead speed of $0.254 \mathrm{~mm} / \mathrm{minute}$ and the sample displacement was measured with a laser extensometer.

\subsection{Characterization: Optical Microscopy, eSEM, X-ray Mapping, Tomography}

In order to calculate the fracture toughness, post fracture optical microscopy was required to measure the semi-elliptical surface crack for the Knoop and the single edge notch for the Laser V-notch. Each notched or surface cracked sample was photographed using a Keyence VHX 1000 digital microscope. Figure 3b \& c shows OM's of the thumbnail, which was measured and used for fracture toughness calculation for the SCF tests. No measurements were needed for the $\mathrm{CN}$ samples because the method does not require pre-cracking. 


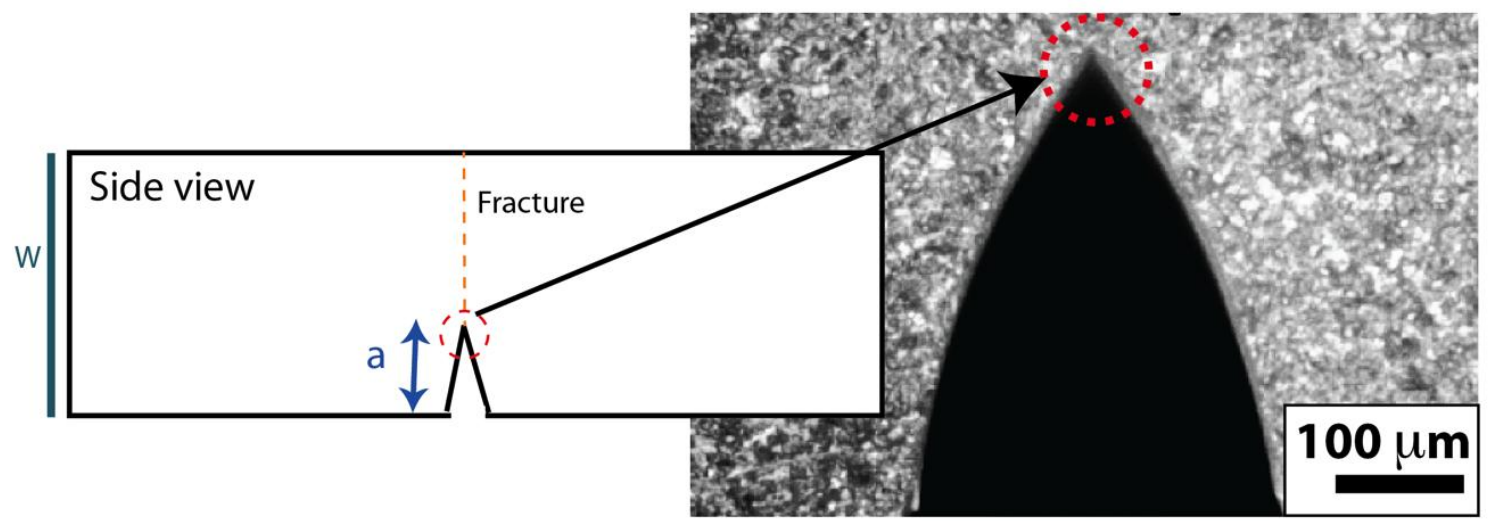

Figure 3. Schematic showing the laser V-notch sample geometry and an optical microscope image showing a close up side view of the V-notch in an alumina sample introduced with a picosecond laser. This is a representative example of the size of the root radius of a laser notched in a high purity alumina specimen, which has a root radius of approximately $<10 \mu \mathrm{m}$.

Scanning Electron Microscopy (SEM) was used to investigate the microstructure of each type of alumina $(96 \%, 97.5 \%, 99.5 \%)$ prior to mechanical testing. After the mechanical tests were performed, post fracture qualitative observations of the fracture surface, failure modes, and impurity distribution were made using an eSEM and X-ray mapping via Energy Dispersive Spectroscopy (EDS). The impurity elements of interest were silicon, calcium, and sodium. The secondary electron, backscattered electron and x-ray maps were acquired on a JEOL-8200 electron microprobe operating at $15 \mathrm{kV}$ with a tungsten wire filament. Secondary electron maps were acquired with a beam current of 1 na, while backscattered electron and energy dispersive x-ray maps were digitally acquired over a $1024 \times 1024$ pixel grid with a dwell time of $5 \mathrm{msec} /$ pixel using a beam current of 20 na. 
Synchrotron Radiation micro-Tomography was used to investigate the notch and the surrounding material in 3-dimensions for several of the laser notched specimens. The tomographic imaging was performed at beamline 8.3.2 at the Advanced Light Source (Lawrence Berkeley National Laboratory, Berkeley, Ca, USA) in monochromatic mode at an energy of $24 \mathrm{keV}$. The setup used was similar to standard tomographic procedures [22] where the sample is rotated 180 degrees in an X-ray beam and the transmitted radiographic projections (1025 images total per data set) are imaged via a scintillator, magnifying lens, and a digital camera to give an effective voxel size of $3.3 \mu \mathrm{m}^{3}$. The reconstructed images were obtained via a filtered back projection algorithm. Each data set was reconstructed using the software Octopus [23] and the three-dimensional visualization of the internal structure was performed using Avizo ${ }^{\mathrm{TM}}$ [24] software.

\section{Results and Discussion}

For comparison purposes, fracture toughness testing was carried out on alumina samples using the SEVNB, CN, and SCF methods. Each testing method was assessed based on relative ease of notching or pre-cracking and mechanical testing, as well as the amount of time required for necessary post-fracture observations used in determining the fracture toughness.

The time spent conducting sample preparation and deciding on setup for the different methods studied here varied greatly due to the different requirements for test sample geometry. For the SCF method only one sacrificial alumina piece was used for selecting 
load and indenter tip. Pre-cracking with an indenter tip proved to be relatively easy for systematically introducing a surface crack in each specimen. No new fixtures or equipment was needed for this process. In contrast, the $\mathrm{CN}$ method required custombuilt fixtures designed to machine the chevron geometry into an alumina specimen. Once the fixture was designed, which was sample size and notch geometry specific, the alignment of the notch proved to be quite difficult and time consuming to perform. For the ps laser SEVNB method, the laser-assisted-machining step only required one sacrificial alumina specimen to test different laser parameters, once the parameters were selected the process of notching proved to be very fast, each sample taking under 2 minutes to notch. An image of a typical ps laser notched high purity alumina is shown in Figure 3, which shows an OM of the side profile of a sample in the cut condition. The root radius was measured as $<10 \mu \mathrm{m}$. The notch is further investigated by imaging in 3D, as shown in Figure 4, where it is shown that the notch has a consistent measured radius throughout the specimen's thickness. Also, unwanted damage was observed in the surrounding material. 


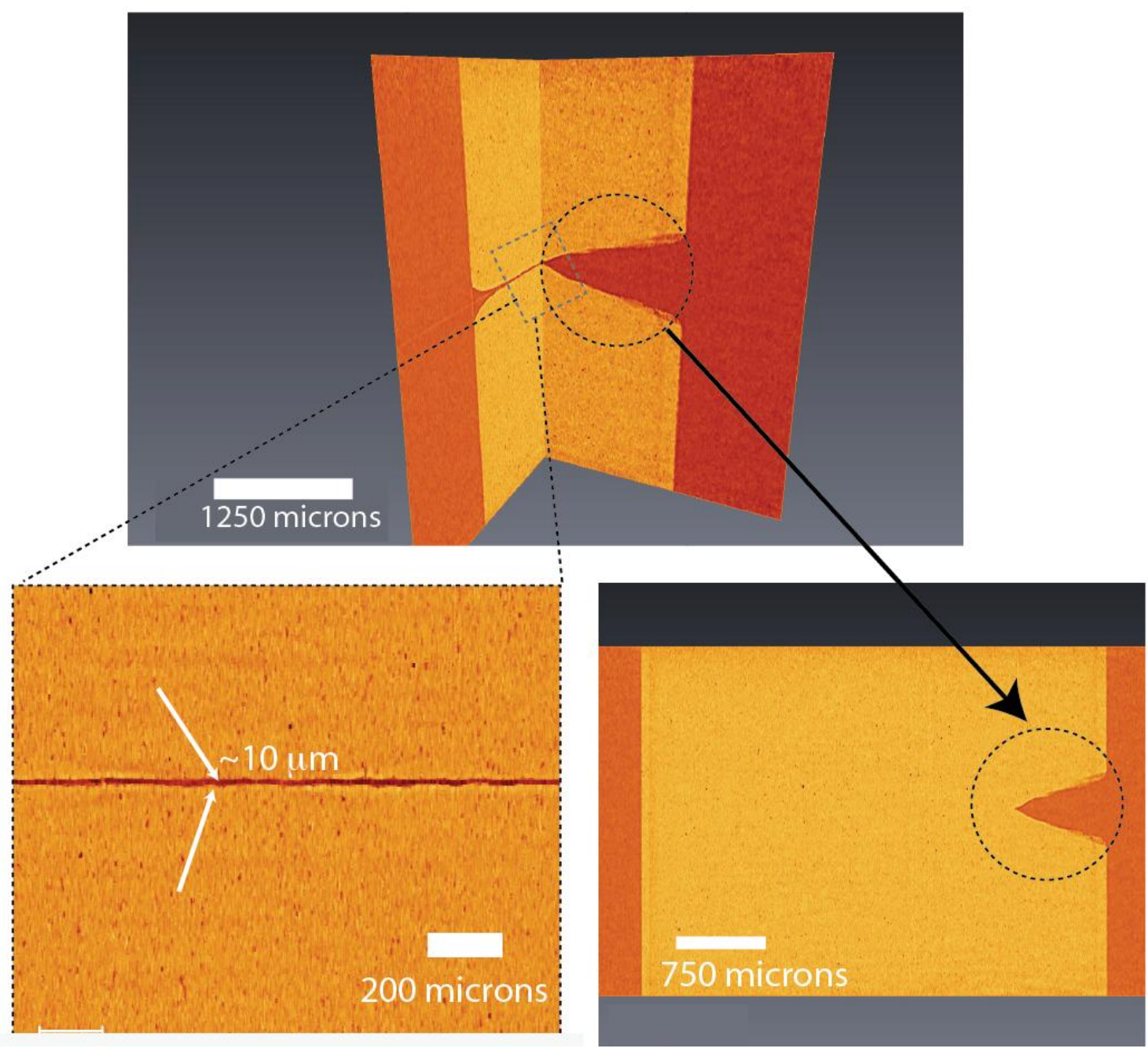

Figure 4. Synchrotron Radiation micro-Tomographic images of a laser notched $96 \%$ alumina bend sample prior to mechanical testing. The two different views are $90^{\circ}$ cross-sections showing the notch's side view and front view. Tomographic slice a few microns away from the notch tip the height of the notch is measured to be $10 \mu \mathrm{m}$. This is smaller than is achievable with most scribing methods such as using a razor blades, which can be limited to the width of the blade.

The appendix describes the calculations used to determine the fracture toughness values using each of the methods studied here. The flexure strength and fracture toughness 
results using the $\mathrm{CN}, \mathrm{SEVNB}$, and SCF methods are summarized in Table 3. Table 3 includes the mean value and standard deviations for all of the mechanical test results for all three types of aluminum oxide. When comparing the measured flexure strength and fracture toughness values it is worth noting that the $96 \%$ alumina was taken from a batch of alumina without a certification sheet. It was observed that the flexure strength was found to be highest for the alumina with the smallest grain size which is typical of what is reported in the literature [25], but it's fracture toughness was found to be the lowest of all three types of alumina. Since we have such low statistics from the $\mathrm{CN}$ method it is difficult to compare measured fracture toughness against the other two methods. Overall, the average fracture toughness was found to be highest for $97.5 \%$ alumina using the SCF and CN methods, but not with the SEVNB method. These results show that different methods can result in different comparative fracture toughness values for the same material. Figure 5 shows a graph comparing the SCF and the SEVNB fracture toughness results for the three types of alumina. These results show that the highest statistical variation for alumina's fracture toughness occurred with the SCF tests. Indeed, for Knoop indentation we found that the measurement error was sample and purity dependent. For example, one sample had a pre-crack which was measured by two different scientists and the subjectivity of the measurements produced fracture toughness results that varied by $0.4 \mathrm{MPa} \sqrt{\mathrm{m}}$. This discrepancy in fracture toughness results is unacceptable when performing any study where accuracy is important. 


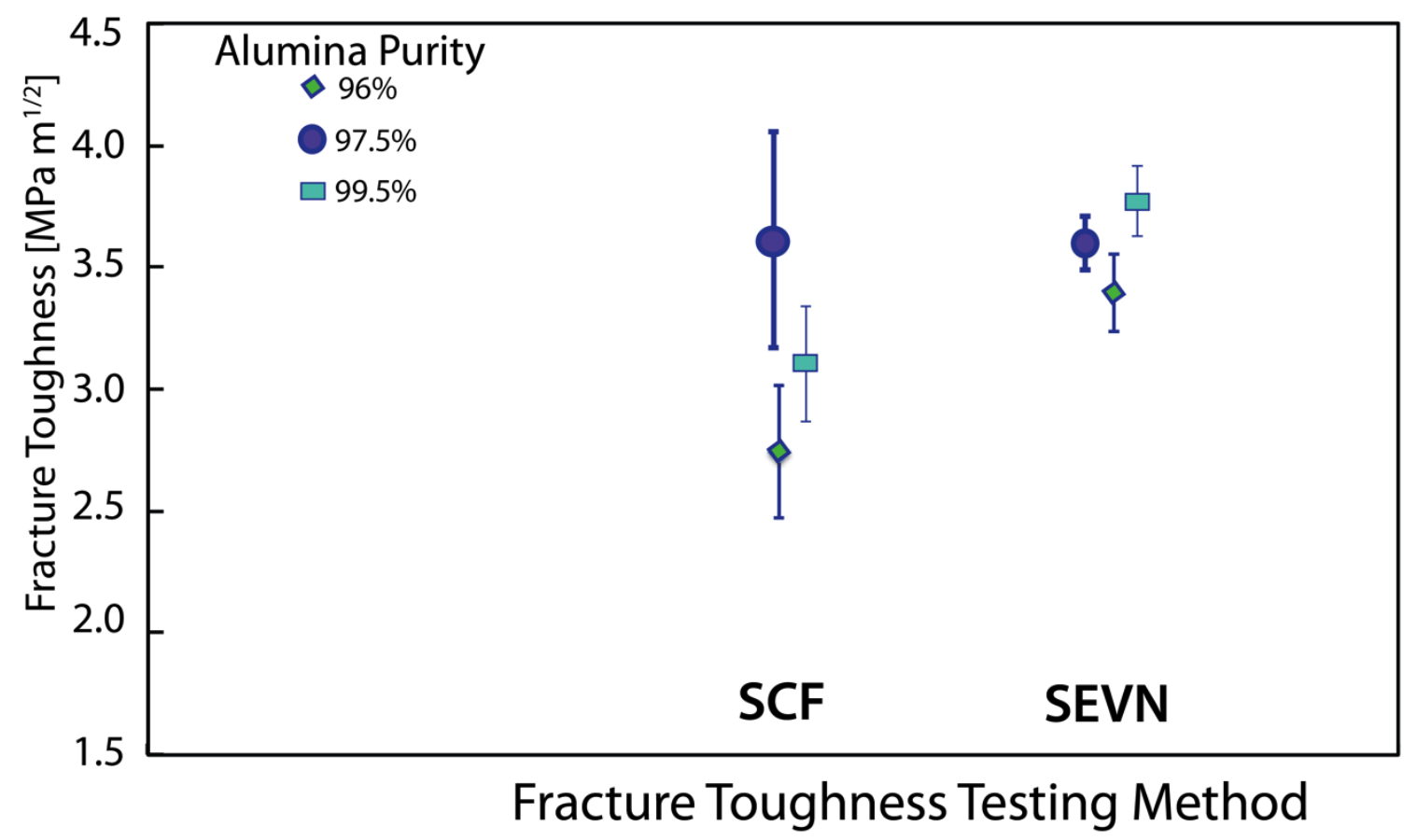

Figure 5. Plot comparing the variability in fracture toughness measured by the Knoop SCF and laser SEVNB methods. 
Table 3. Mechanical test results showing the calculated values of the average strength and toughness and the standard deviation for each type of aluminum oxide $(96 \%, 97.5 \%$, and $99.5 \%)$. The fracture toughness was measured using three methods, SEVNBB, SCF, and CN. Here $\mathrm{n}$ is the number of specimens tested. Also shown her is the grain size of each type of alumina.

\begin{tabular}{|c|c|c|c|c|c|}
\hline \multirow{2}{*}{$\%$ of $\mathrm{Al}_{2} \mathrm{O}_{3}$} & \multirow{2}{*}{$\begin{array}{c}\text { Grain } \\
\text { Size } \\
{[\mu \mathrm{m}]}\end{array}$} & \multirow{2}{*}{$\begin{array}{c}\text { Flexure } \\
\text { Strength } \\
\\
(\mathrm{n}=3) \\
{[\mathrm{MPa}}\end{array}$} & \multicolumn{3}{|c|}{ Fracture Toughness } \\
\hline & & & $\begin{array}{c}\text { SEVNBB } \\
(\mathrm{n}=3-6) \\
{[\mathrm{MPa} \sqrt{\mathrm{m}}]}\end{array}$ & $\begin{array}{c}\text { SCF } \\
(\mathrm{n}=5) \\
{[\mathrm{MPa} \sqrt{\mathrm{m}}]}\end{array}$ & $\begin{array}{c}\mathrm{CN}^{* *} \\
(\mathrm{n}=2) \\
{[\mathrm{MPa} \sqrt{\mathrm{m}}]}\end{array}$ \\
\hline 96 & $\sim 7$ & $342+/-14$ & $3.39+/-0.16$ & $2.74+/-0.27$ & $3.43+/-0.03$ \\
\hline 97.5 & $\sim 30$ & $216+/-10$ & $3.60+/-0.11$ & $3.61+/-0.44$ & $4.04+/-0.13$ \\
\hline 99.5 & $\sim 10$ & $319+/-33$ & $3.75+/-0.17$ & $3.10+/-0.24$ & $3.66+/-0.06$ \\
\hline
\end{tabular}

Figures $6 \& 7$ show representative images of fracture surfaces. Figure 6 shows the X-ray mapping of silicon impurities on the fracture surface for each type of alumina and Figure 7 shows the fracture surface near the notch for SEVNB and the pre-crack for the SCF specimen. Silicon was identified as one of the main impurities found in all three types of alumina. The silicon is known to form silica glass throughout the microstructure, which is very brittle. While silicon was found to be a prominent impurity in all three types of alumina, the distribution and amount of the silicon varied substantially between the three types of alumina. For the larger grain size $97.5 \%$ alumina the silicon formed its own smaller high density areas, while the high purity 99.5\% alumina displayed much less silicon and the silicon was more evenly distributed 
throughout the matrix. Indeed, the grain size and impurity distribution was observed to be different between the three types of alumina.
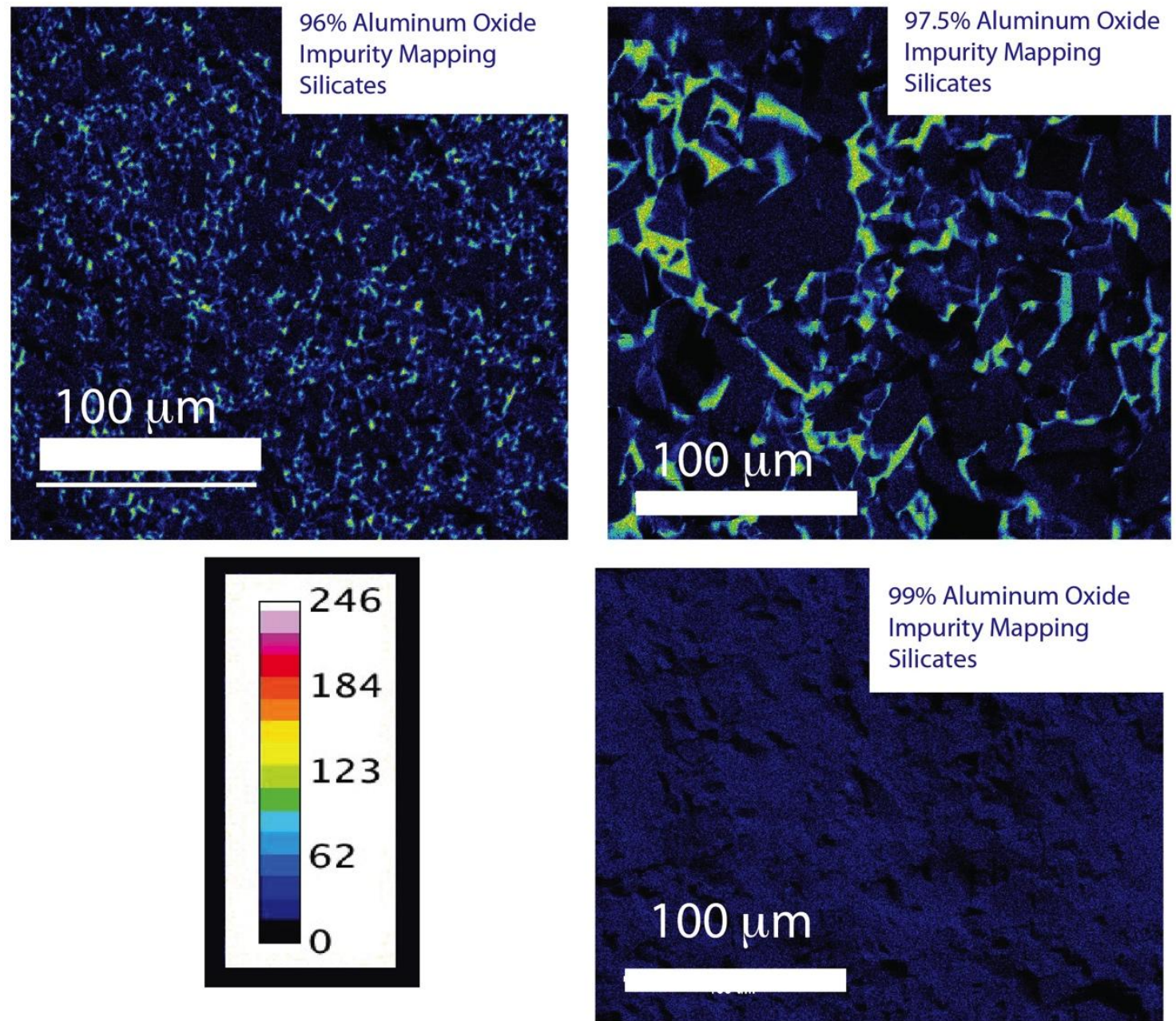

Figure 6. X-ray maps showing the distribution of silicates throughout the microstructure for each of the three purities of alumina. These $\mathrm{x}$-ray maps were taken on a fractured alumina surface. The glassy phase in the $96 \%$ alumina is much smaller than what is observed in the $97.5 \%$ alumina, while the $99.5 \%$ has a much lower presence of silicates, which are evenly distributed throughout the alumina. 
Lastly, we evaluated challenges faced with each method's post-fracture measurements, since SCF and SEVNB methods require a measurement of initial pre-crack or notch size in order to calculate the fracture toughness and the $\mathrm{CN}$ does not. We also investigated whether any unwanted damage was introduced during the specimen's preparation. The SCF method proved to be the most difficult to evaluate the depth of the pre-crack, since, as shown in Figure $3 b$, using an $\mathrm{OM}$ to see the thumbnail leads to uncertainty in the measured crack width and height. The contrast on the fracture surface for measuring the pre-crack was very low and it made it difficult to have high confidence in the measured pre-crack. The SEVNB method required a measurement of the notch depth to get the $\mathrm{a} / \mathrm{W}$ for fracture toughness calculations which was done on the fracture surface. This was measured for each fractured sample and was much easier to discern from the fracture surface. Also, once the parameters for the laser notching were set the notch depth was kept very consistent between samples. Our post fracture investigation of the fracture surface showed that laser-assisted-machine notching did not introduce any noticeable unwanted damage to the specimen as shown in Figures $4 \& 7$, since we used the ps laser, which removes material by cold ablation rather than melting. From the fractography we observed similar failure modes for all three types of notched geometries. However, through SEM it was observed that the grains were crushed in the Knoop indented pre-crack tests as seen in Fig. 7 with cracks emanating ahead radially from the surface crack. This could have been a result of the higher load needed to introduce a discernable surface crack into the alumina and in future tests would have been polished away prior to testing. However, this was not observed until post testing, 
and demonstrates an additional issue or step that could arise when using the SCF method. The advantages and disadvantages from this study are summarized in Table 4.

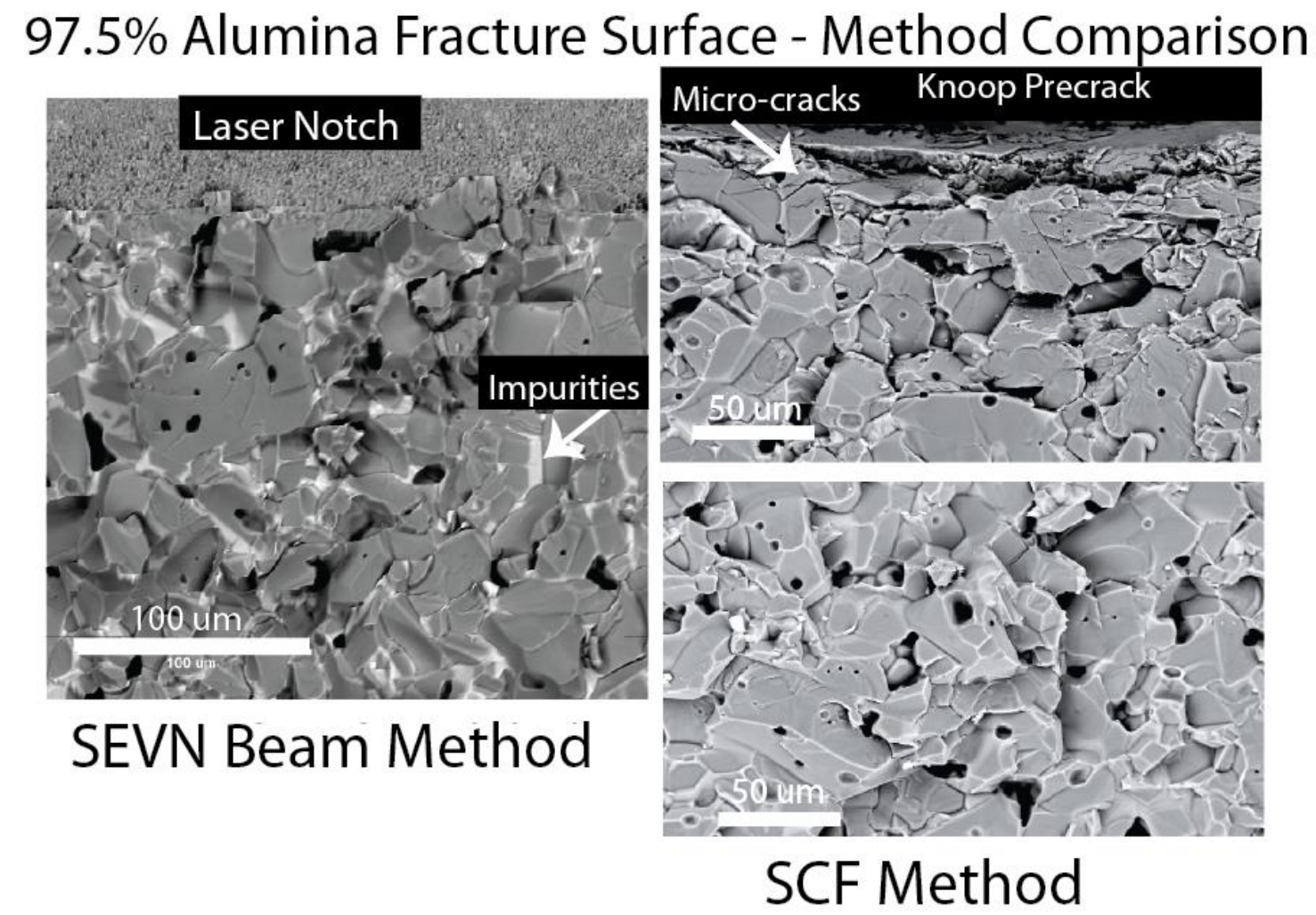

Figure 7. Scanning Electron Micrographs (SEM) showing the fracture surface for the $97.5 \%$ alumina for the SEVNB (laser notched) versus the SCF. It was observed that the grains are crushed under the Knoop indentation load. The holes seen in the SEM images here are believed to be pull out of grains and do not give an accurate representation of porosity in the alumina. 
Table 4. Table discussing the pros and cons of each method for fracture toughness calculations used in this study.

Pros and Cons of Notching Options

\begin{tabular}{lll}
\hline $\begin{array}{l}\text { Fracture } \\
\text { Toughness } \\
\text { Method }\end{array}$ & Pros & Cons \\
\hline $\begin{array}{l}\text { Surface } \\
\text { Crack } \\
\text { Flexure }\end{array}$ & $\begin{array}{l}\text { Easy selection of parameters for } \\
\text { test, i.e., indenter tip, pre-load } \\
\text { selection. }\end{array}$ & $\begin{array}{l}\text { Extremely difficult to measure } \\
\text { pre-crack depth with } \\
\text { confidence, which can lead to } \\
\text { error in the toughness } \\
\text { calculations }\end{array}$ \\
& - Relatively easy to pre-crack & $\begin{array}{l}\text { Susceptible to micro cracking } \\
\text { problems in base material }\end{array}$ \\
& & -
\end{tabular}

Our findings show that this approach, of using a ps laser for notching, is fast and easy to control, as well as reliable for fracture toughness tests on ceramic materials. Specifically, the laser notch technique is shown to produce a root radius smaller than the grain size of all of the alumina samples examined and no observable cracking around the notch tip. 


\section{Summary and Conclusion}

Fracture toughness tests are necessary for understanding the fracture behavior in ceramics. Alumina, for example, displays brittle characteristics common of ceramics and is sensitive to flaws often introduced during the specimen preparation process. In this study we discuss using the SEVNB method for fracture toughness testing and using a picosecond laser to introduce the small radius of the $\mathrm{V}$ notch in aluminum oxide samples $(96,97.5, \& 99.5 \%)$. Other studies have shown the advantage of using laser machining rather than conventional methods on cutting alumina tiles, and the associated advantages of non-contact machining, precision, and low cost [26]. Here, the laser notching studies of alumina confirm the advantages, showing that laser notching can be more economical than conventional mechanical methods and can also produce notches with minimal unwanted damage to the surrounding material for fracture toughness testing of ceramics. Due to this reliability in the notch size, this method should not introduce any uncertainty from measurement errors, which were demonstrated to exist when measuring the surface crack from the SCF method. Indeed, laser notching was shown to produce notches that have a consistent geometry with no noticeable unwanted damage around the notch, and is recommended for notching ceramics or other brittle materials. 


\title{
5. Appendix
}

Fracture Toughness Calculations for SEVNB, CN, and SCF

\author{
Nomenclature for Fracture Toughness Calculations: \\ $\mathrm{a}=$ crack depth or half length of the indentation diagonal \\ $\mathrm{a}_{0}=$ notch depth to chevron tip \\ $a_{i}=$ notch depth along specimen surface \\ $\alpha=$ relative crack depth $(\mathrm{a} / \mathrm{W})$ \\ $\mathrm{B}=$ specimen width \\ $\mathrm{d}=$ notch width \\ $\mathrm{E}=$ Young's modulus \\ $\mathrm{F}=$ indentation load \\ $S_{0}=$ outer span of four point bend fixture \\ $S_{i}=$ inner span four point bending fixture \\ $\mathrm{Fc}=$ fracture load \\ $\mathrm{B}=$ specimen thickness \\ $\mathrm{W}=$ specimen height (also called width in the text) \\ $\mathrm{Y}=$ Stress Intensity shape factor
}

\section{Fracture Toughness Calculations for SEVNB}

The calculations for SEVNB tests are shown below. 


$$
K_{I C}=\frac{F_{C}}{B \sqrt{W}} * \frac{\left(S_{o}-S_{i)}\right.}{W} * \frac{3 \sqrt{\alpha}}{2(1-\alpha)^{1.5}} * Y^{\prime}
$$

Where

$$
Y^{\prime}=1.9887-1.326 \alpha-\left(3.49-0.68 \alpha+1.35 \alpha^{2}\right) \alpha(1-\alpha)(1+\alpha)^{-2}
$$

Fracture Toughness Calculations for CN Bend Tests

The calculations for Chevron-Notch bend tests are shown below.

$$
K_{I v b}=Y_{\min }^{*}\left[\frac{P_{\max }\left[S_{o}-S_{i}\right] 10^{-6}}{B W^{\frac{3}{2}}}\right]
$$

$$
\begin{aligned}
& Y_{\min }^{*}=Y_{\min }^{*}\left(\frac{a_{0}}{W}, \frac{a_{1}}{W}\right) \\
& =\frac{0.3874-3.0919\left(a_{0} / W\right)+4.2017\left(a_{1} / W\right)-2.3127\left(a_{1} / W\right)^{2}+0.6379\left(a_{1} / W\right)^{3}}{1.0000-2.9686\left(a_{0} / W\right)+3.5056\left(a_{0} / W\right)^{2}-2.1374\left(a_{0} / W\right)^{3}+0.0130\left(a_{1} /_{W}\right)}
\end{aligned}
$$

\section{Fracture Toughness Calculations for Surface-Crack Flexure Tests}

The calculations for Knoop indentation flexure tests are shown below. 
For the deepest point in the pre-crack:

$$
\begin{aligned}
& Y_{d}=\frac{\left[\sqrt{\pi} M H_{2}\right]}{\sqrt{Q}} \\
& Q=Q\left(\frac{a}{c}\right)=1+1.464\left[\frac{a}{c}\right]^{1.65} \\
& H_{2}=H_{2}\left(\frac{a}{c}, \frac{a}{W}\right)=1-\left[1.22+0.12\left[\frac{\mathrm{a}}{\mathrm{c}}\right]\right]\left[\frac{\mathrm{a}}{\mathrm{W}}\right]+\left[0.55-1.05\left[\frac{\mathrm{a}}{\mathrm{c}}\right]^{0.75}+0.47\left[\frac{a}{W}\right]^{1.5}\right]\left[\frac{a}{W}\right]^{2} \\
& M=M\left(\frac{a}{c}, \frac{a}{W}\right) \\
& =\left[1.13-0.09\left[\frac{a}{c}\right]\right]+\left[-0.54+\frac{0.89}{\left[0.2+\left[\frac{a}{c}\right]\right]}\right]\left[\frac{a}{W}\right]^{2} \\
& +\left[0.5-\frac{1}{\left[0.65+\left[\frac{a}{c}\right]\right]}+14\left[1-\frac{a}{c}\right]^{24}\right]\left[\frac{a}{W}\right]^{4}
\end{aligned}
$$

For the point at the surface:

$$
Y_{S}=\frac{\left[\sqrt{\pi} M H_{1} S\right]}{\sqrt{Q}}
$$




$$
\begin{gathered}
H_{1}=H_{1}\left(\frac{a}{c}, \frac{a}{W}\right)=1-\left[0.34+0.11\left[\frac{a}{c}\right]\right]\left[\frac{a}{W}\right] \\
S=S\left(\frac{a}{c}, \frac{a}{W}\right)=\left[1.1+0.35\left[\frac{a}{W}\right]^{2}\right] \sqrt{a / c}
\end{gathered}
$$

Use the greatest value of $Y_{d}$ or $Y_{s}$ for $Y$ in the fracture toughness calculations:

$$
K_{I S C}=Y\left[\frac{3 P_{\max }\left[S_{0}-S_{i}\right] 10^{-6}}{2 B W^{2}}\right] \sqrt{a}
$$




\section{References}

[1] M. Munro. Evaluated Material Properties for a Sintered alpha-Alumina, J Amer Ceram Soc 80 (1997) 1919-1928.

[2] G.D. Quinn. Flexure Strength of Advanced Ceramics: A Round Robin Exercise, Rept. No. MTL TR 89-62, U.S. Army Materials Technology Laboratory, Watertown, MA (1989).

[3] M.E. Launey, R.O. Ritchie. On the Fracture Toughness of Advanced Materials, Adv Mater 21 (2009) 2103-2110.

[4] ASTM C1421 - 10. Standard Test Methods for Determination of Fracture Toughness of Advanced Ceramics at Ambient Temperature.

[5] G.D. Quinn, R.J. Gettings, J.J. Kübler. Fracture Toughness by the Surface Crack in Flexure (SCF) Method: Results of the Vamas Round Robin. Proceedings of the 18th Annual Conference on Composites and Advanced Ceramic Materials-B: Ceramic Engineering and Science Proceedings. John Wiley \& Sons, Inc., 2008. pp. 846-855.

[6] C.A. Tracy, G.D. Quinn. Fracture Toughness by the Surface Crack in Flexure (SCF) Method. Proceedings of the 18th Annual Conference on Composites and Advanced Ceramic Materials-B: Ceramic Engineering and Science Proceedings. John Wiley \& Sons, Inc., 2008. pp. 836-845.

[7] D. Munz, R.T. Bubsey, J.L. Shannon. Fracture Toughness Determination of A1203 Using Four-Point-Bend Specimens with Straight-Through and Chevron Notches, J Am Ceram Soc 63 (1980) 300-305.

[8] B. Lawn. Fracture of Brittle Solids, Cambridge Solid State Science Series, 1993.

[9] K. Strecker, S. Ribeiro, M. Hoffman. Fracture toughness measurements of LPSSiC: a comparison of the indentation technique and the SEVNB method, Mater Research 8 (2005) 121-124.

[10] G. Gogotsi, S. Mudrik, V. Galenko. Evaluation of fracture resistance of ceramics: Edge fracture tests, Ceramics International 33 (2007) 315-320.

[11] J. Kubler. Fracture Toughness of Ceramics using the SEVNB Method; Round Robin (Single-Edge-V-Notched Beam), VAMAS Report No.37 (1999).

[12] R.J. Primas, R. Gstrein. ESIS TC 6 Round Robin on Fracture Toughness, Fatigue Fract Eng M 20 (1997) 513-532.

[13] S.S. Scherrer, I.L. Denry, H.W.A. Wiskott. Comparison of three fracture toughness testing techniques using a dental glass and a dental ceramic, Dent Mater 14 (1998) 246-255.

[14] T. Nishida, Y. Hanaki, G. Pezzotti. Effect of Notch-Root Radius on the Fracture Toughness of a Fine-Grained Alumina, J Am Ceram Soc 77 (1994) 606-608.

[15] R. Damani, R. Gstrein, R. Danzer. Critical notch-root radius effect in SENB-S fracture toughness testing, J Eur Ceram Soc 16 (1996) 695-702.

[16] M.D. Perry, B.C. Stuart, P.S. Banks, M.D. Feit, V. Yanovsky, A.M. Rubenchik. Ultrashort-pulse laser machining of dielectric materials, J App Phys 85 (1999) 68036810 . 
[17] M. Turon-Vinas, M. Anglada. Fracture toughness of zirconia from a shallow notch produced by ultra-short pulsed laser ablation, J Eur Ceram Soc 34 (2014) 3865-3870.

[18] T. Fett, W. Hartlieb, K. Keller, B. Knecht, D. Münz, W. Rieger. Subcritical crack growth in high-grade alumina, Journal of Nuclear Materials 184 (1991) 39-46.

[19] J.W. Elmer, O. Yaglioglu, R.D. Schaeffer, G. Kardos, O. Derkach. Direct patterning of vertically aligned carbon nanotube arrays to $20 \mu \mathrm{m}$ pitch using focused laser beam micromachining, Carbon 50 (2012) 4114-4122.

[20] J. Quinn, G. Quinn. Indentation brittleness of ceramics: a fresh approach, J Mater Sci 32 (1997) 4331-4346.

[21] ASTM Standard C1161-90. Standard Test Method for Flexural Strength of Advanced Ceramics at Ambient Temperature.

[22] J.H. Kinney, M.C. Nichols. X-Ray Tomographic Microscopy (XTM) Using Synchrotron Radiation, Annu Rev Mater Sci 22 (1992) 121-152.

[23] D.M. Vlassenbroeck J, Masschaele B, Cnudde V, Van Hoorebeke L, Jacob P. Software tools for quantification of x-ray microtomography at the 'Center for X-ray Tomography' at Ghent University. Nucl Instru Meth Physics Res A 2007. p.442-445.

[24] Avizo $^{\mathrm{TM}}$ 3D visualization framework. Chelmsford, MA.: Mercury CS, 2008.

[25] W.H. Tuan, M.J. Lai, M.C. Lin, C.C. Chan, S.C. Chiu. The mechanical performance of alumina as a function of grain size, Mater Chem Phys 36 (1994) 246-251.

[26] B.S. Yilbas, S.S. Akhtar, C. Karatas. Laser cutting of rectangular geometry into alumina tiles, Opt Laser Eng 55 (2014) 35-43. 


\section{Acknowledgements}

The authors would like to acknowledge James Embree for his work machining the specimens and fabricating the test fixtures. This work was performed under the auspices of the U.S. Department of Energy by Lawrence Livermore National Laboratory under Contract DE-AC52-07NA27344. The Advanced Light Source is

supported by the Director, Office of Science, Office of Basic Energy Sciences, of the U.S. Department of Energy under Contract No. DE-AC02-05CH11231. 